Chapman University

Chapman University Digital Commons

Pharmacy Faculty Articles and Research

School of Pharmacy

8-18-2018

\title{
UPLC-MS/MS Analysis of Dextromethorphan- O-demethylation Kinetics in Rat Brain Microsomes
}

\author{
Barent N. DuBois \\ Chapman University \\ Reza Mehvar \\ Chapman University, mehvar@chapman.edu
}

Follow this and additional works at: https://digitalcommons.chapman.edu/pharmacy_articles

Part of the Animal Experimentation and Research Commons, Biological Phenomena, Cell Phenomena, and Immunity Commons, Cell Biology Commons, Chemical and Pharmacologic

Phenomena Commons, Medical Cell Biology Commons, Medicinal and Pharmaceutical Chemistry Commons, and the Other Pharmacy and Pharmaceutical Sciences Commons

\section{Recommended Citation}

DuBois BN, Mehvar R. UPLC-MS/MS analysis of dextromethorphan-O-demethylation kinetics in rat brain microsomes. J Chromatogr B. 2018;1096:66-72. doi: 10.1016/j.jchromb.2018.08.011

This Article is brought to you for free and open access by the School of Pharmacy at Chapman University Digital Commons. It has been accepted for inclusion in Pharmacy Faculty Articles and Research by an authorized administrator of Chapman University Digital Commons. For more information,

please contact laughtin@chapman.edu. 


\section{UPLC-MS/MS Analysis of Dextromethorphan-O-demethylation Kinetics in Rat Brain Microsomes}

\section{Comments}

NOTICE: this is the author's version of a work that was accepted for publication in Journal of Chromatography $B$. Changes resulting from the publishing process, such as peer review, editing, corrections, structural formatting, and other quality control mechanisms may not be reflected in this document. Changes may have been made to this work since it was submitted for publication. A definitive version was subsequently published in Journal of Chromatography B, volume 1096, in 2018. DOI:10.1016/j.jchromb.2018.08.011

The Creative Commons license below applies only to this version of the article.

\section{Creative Commons License}

\section{(c) 1 (1) 9}

This work is licensed under a Creative Commons Attribution-Noncommercial-No Derivative Works 4.0 License.

\section{Copyright}

Elsevier 


\section{Accepted Manuscript}

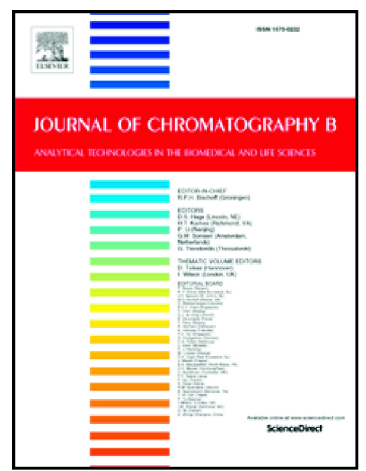

UPLC-MS/MS analysis of dextromethorphan-O-demethylation kinetics in rat brain microsomes

Barent N. DuBois, Reza Mehvar

S1570-0232(18)30972-3

PII: doi:10.1016/j.jchromb.2018.08.011

Reference:

CHROMB 21327

To appear in:

Journal of Chromatography B

Received date:

22 June 2018

Revised date:

15 August 2018

Accepted date:

17 August 2018

Please cite this article as: Barent N. DuBois, Reza Mehvar, UPLC-MS/MS analysis of dextromethorphan-O-demethylation kinetics in rat brain microsomes. Chromb (2018), doi:10.1016/j.jchromb.2018.08.011

This is a PDF file of an unedited manuscript that has been accepted for publication. As a service to our customers we are providing this early version of the manuscript. The manuscript will undergo copyediting, typesetting, and review of the resulting proof before it is published in its final form. Please note that during the production process errors may be discovered which could affect the content, and all legal disclaimers that apply to the journal pertain. 


\section{Short Communication}

UPLC-MS/MS analysis of dextromethorphan-O-demethylation kinetics in rat brain microsomes

Barent N. DuBois ${ }^{\mathrm{a}}$, Reza Mehvar, ${ }^{\mathrm{a}, *}$

${ }^{a}$ Department of Biomedical and Pharmaceutical Sciences, School of Pharmacy, Chapman University, Irvine, USA

* Corresponding author at: Department of Biomedical and Pharmaceutical Sciences, Rinker Health Science Campus, Chapman University, 9401 Jeronimo Road, Irvine, CA 92168, USA. Tel.: +1 714516 5490; fax: +1 714516 5481.; E-mail address: mehvar@chapman.edu. 


\section{ABSTRACT}

Formation of dextrorphan (DXT) from dextromethorphan (DXM) has been widely used to assess cytochrome P450 2D (CYP2D) activity. Additionally, the kinetics of CYP2D activity have been well characterized in the liver microsomes. However, studies in brain microsomes are limited due to the lower microsomal content and abundance of CYP2D in the brain relative to the liver. In the present study, we developed a micro-scale enzymatic incubation method, coupled with a sensitive UPLC-MS/MS assay for the quantitation of the rate of DXT formation from DXM in brain microsomes. Rat brain microsomes were incubated with different concentrations of DXM for various times. The reaction was stopped, and the proteins were precipitated by the addition of acetonitrile, containing internal standard $\left(\mathrm{d}_{3}\right.$-DXT). After centrifugation, supernatant $(2 \mu \mathrm{L})$ was injected onto a UPLC, C18 column with gradient elution. Analytes were quantitated using triple-quadrupole MS/MS with electrospray ionization in positive ion mode. The assay, which was validated for accuracy and precision in the linear range of $0.25 \mathrm{nM}$ to $100 \mathrm{nM}$ DXT, has a lower limit of quantitation of $0.125 \mathrm{fmol}$ on the column. Using our optimized incubation and quantitation methods, we were able to reduce the incubation volume $(25 \mu \mathrm{L})$, microsomal protein amount $(5 \mu \mathrm{g})$, and incubation time (20 min), compared with reported methods. The method was successfully applied to estimation of the Michaelis-Menten (MM) kinetic parameters of dextromethorphan-O-demethylase activity in the rat brain microsomes (mean $\pm \mathrm{SD}, n=4$ ), which showed a maximum velocity of $2.24 \pm 0.42 \mathrm{pmol} / \mathrm{min} / \mathrm{mg}$ and a MM constant of $282 \pm 62$ $\mu \mathrm{M}$. It is concluded that by requiring far less biological material and time, our method represents a significant improvement over the existing techniques for investigation of CYP2D activity in rat brain microsomes. 
Keywords:

UPLC-MS/MS

CYP2D

Dextromethorphan-O-demethylase

Brain

Microsomes

Michaelis-Menten kinetics 


\section{Introduction}

The dextromethorphan-O-demethylase (DOD) activity assay, where dextromethorphan (DXM) is biotransformed into the metabolite dextrorphan (DXT) (Fig. 1), is a commonly used tool to estimate cytochrome P450 (CYP) 2D6 (CYP2D6) function in humans [1, 2]. The DOD assay is also used in animal studies (especially in rats) to compare human CYP2D6 substrate specificities with those in other species [3-7]. In rodents, this activity is more generally assigned to the CYP2D subfamily, given there are multiple isoforms within this subfamily with similar homology and substrate affinities that overlap with the human CYP2D6 isoform [8-10].

In both humans and rats, CYP2D is expressed in both the liver and brain [11-13]. Although the liver is considered the main site of drug clearance and metabolism, studies have shown that the expression and activity of CYP2D in the brain can alter pharmacologic responses to centrally-acting drug [5, 6, 12, 14-17]. Functional characterization of CYP enzymes in vitro is typically achieved via subcellular fractionation and collection of the small vesicles formed by the endoplasmic reticulum, called microsomes. Hepatic microsomes are routinely used in drug metabolism assays given the high abundance of CYP protein located there [2]. The principal limitation for functional assays of CYP enzymes in the brain is their relatively low abundance, which is approximately $1-4 \%$ of that in the liver with the exception of some specific brain regions $[11,13,18]$. Indeed, the microsomal protein content in the brain $(2-4 \mathrm{mg}$ per gram of brain tissue) [19] is much lower relative to that in the liver (30-40 mg per gram of liver tissue) [20]. In rodent studies, this limitation is exacerbated by the small quantity of brain tissue in these species. Thus, there are few studies in the literature where the characterization of DOD kinetics in the brain microsomes has been attempted $[3,4,7]$. 
The reported in vitro studies of CYP2D activity in rat brain microsomes $[3,4,7]$ tend to utilize much higher protein concentrations $(50-1500 \mu \mathrm{g})$ and much longer incubation times (1 to 2 hours) than what are typically used with the hepatic microsomes. These conditions are apparently necessary so that the reaction can produce enough metabolite to be accurately quantified. However, this exacerbates the issue of overall lower amounts of microsomal protein available from a single brain, such that pooling of several brains to generate enough material for these assays is necessary $[3,4,7]$. Other studies $[5,6,10]$ have utilized something called the "total membrane fraction," which is a pooling of both mitochondrial and microsomal membranes, to increase yield. However, these studies $[5,6,10]$ still require long incubation times (2-3 hours) and high protein quantities (1.5-3 $\mathrm{mg}$ membrane protein/reaction).

To circumvent the barriers in the studies of DOD activity in rodent brain tissue, we present here an optimized micro-scale enzymatic incubation method, coupled with a validated and sensitive UPLC-MS/MS assay for quantification of DOD activity in rat brain microsomes. The relatively high analytical sensitivity of the assay, along with the use of a pure DXM substrate that is devoid of DXT impurity, allowed us to measure the lower concentrations of DXT produced at relatively low microsomal protein amounts and short incubation periods. The application of the method to determination of the Michaelis-Menten (MM) kinetic parameters of DXM demethylation in rat brain microsomes is also demonstrated. This method will be useful when applied to animal studies investigating the effect of drug-drug interactions or disease pathologies related to the CYP2D activity in the brain. 


\section{Materials and methods}

\subsection{Chemicals}

Three different stock sources for dextromethorphan hydrobromide salt (DXM-HBr) were purchased from Sigma-Aldrich (St. Louis, MO, USA): DXM-HBr \#1 (catalog \#: D9684), DXMHBr \#2 (catalog \#: PHR1018), and DXM-HBr \#3 (catalog \#: D2531). Dextromethorphan base reference standard (DXM-USP) was purchased from the United States Pharmacopeial Convention (Rockville, MD, USA). Analytical metabolite standard solutions for DXT tartrate and its stable isotope $\mathrm{d}_{3}$-DXT were purchased from Cerilliant Corporation (Round Rock, TX, USA). UPLC/LC-MS grade solvents (acetonitrile, methanol, and water) were purchased from VWR (Radnor, PA, USA). All other reagents were analytical grade and were obtained from commercial sources.

\subsection{Instrumentation}

The UPLC-MS/MS system consisted of a Bruker EVOQ triple quadrupole mass spectrometer, attached to the Bruker Advance UPLC system with an integrated column oven, degasser, and a CTC PAL autosampler. The system was controlled and the data acquired and quantified by the Bruker MSWS 8 software. The chromatographic separation was achieved using a Phenomenex Kinetex 1.7 um C18 (100 A, 50 x $2.1 \mathrm{~mm})$ column, connected to a Phenomenex C18 SecurityGuard ULTRA $(2.1 \mathrm{~mm})$ pre-column and maintained at $40^{\circ} \mathrm{C}$. Samples $(2 \mu \mathrm{L})$ were injected onto the column and eluted at a flow rate of $0.2 \mathrm{~mL} / \mathrm{min}$ under gradient conditions consisting of solvent A (5 mM ammonium formate: formic acid, 100:0.05) and solvent B (acetonitrile: methanol: formic acid, 95:5:0.05). Gradient conditions were as follows: 0-0.5 minutes, 10\% B; 0.5-4 min, linear gradient 10-90\% B; 4-7 min, 90\% B; 7 min, 10\% B; 7-9 min, 
$10 \%$ B. However, MS data were collected from 1 to $4 \mathrm{~min}$ only, and the valve was diverted to waste before and after that time.

The mass spectrometer source utilized heated electrospray ionization (needle temperate $300^{\circ} \mathrm{C}$, flow $40 \mathrm{psi}$; cone temperature $300^{\circ} \mathrm{C}$, flow 20 psi; nebulizer gas flow 50 psi) in positive ion mode at $3000 \mathrm{~V}$. Metabolite and internal standard (IS) were analyzed using selected reaction monitoring for the parent/fragment transitions for DXT $(\mathrm{m} / \mathrm{z} 258 \rightarrow 156.90)$ and $\mathrm{d}_{3}-\mathrm{DXT}(\mathrm{m} / \mathrm{z}$ $261 \rightarrow 156.90)$

\subsection{Standard curves}

Stock solutions of DXT tartrate (equivalent to $1 \mathrm{mg} / \mathrm{mL}$ DXT base in methanol) and $\mathrm{d}_{3}$-DXT (100 $\mu \mathrm{g} / \mathrm{mL}$ in methanol) were used as supplied by Cerilliant. Dextrorphan tartrate was diluted to a concentration of $1 \mu \mathrm{g} / \mathrm{mL}$ (DXT base) in acetonitrile, and then further diluted to a working stock solution of $200 \mathrm{nM}$ in $100 \mathrm{mM}$ Tris buffer. For calibration curves, blank samples containing $0.2 \mathrm{mg} / \mathrm{mL}$ brain microsomal protein in Tris buffer were spiked with stock solutions in buffer to give concentrations of $0.25,0.5,1,2,5,10,20,50$, and $100 \mathrm{nM}$. The internal standard $\mathrm{d}_{3}$-DXT was diluted to $10 \mathrm{nM}$ in acetonitrile. Calibration curves were constructed by plotting the analyte: IS peak area ratios versus the added concentrations of DXT.

\subsection{Sample preparation}

Calibration standards or metabolic incubation samples $(25 \mu \mathrm{L})$ in a microcentrifuge tube were mixed with $75 \mu \mathrm{L}$ of an ice-cold solution of IS (10 nM) in acetonitrile. Subsequently, tubes were vortex-mixed for $10 \mathrm{sec}$ and centrifuged at 12,000 g-force for 5 minutes to precipitate proteins. The supernatant was collected into HPLC vials for analysis.

\subsection{Method validation}

\subsubsection{Accuracy and precision}


The inter- and intra-run accuracies and precision of the method were evaluated based on the quantitation of quality controls at DXT concentrations of $0.25,5$, and $100 \mathrm{nM}(n=5$ per each concentration) against calibration standards, which were prepared from different stock solutions. The accuracy was calculated by measured concentration x 100/nominal concentration. Precision was calculated as a percent of the relative standard deviation (R.S.D). The acceptable range for both inter- and intra-run accuracies was considered $85-115 \%$ for middle and high concentrations, and $80-120 \%$ for the low concentration [21]. The acceptable precision values were $15 \%$ (middle and high concentrations) and 20\% (low concentration) [21].

\subsubsection{Linearity}

The linearity of the calibration curves was evaluated by the coefficient of determination $\left(r^{2}\right)$ of the linear regression analysis of the analyte: IS peak area ratios versus spiked concentrations of DXT using a weight of $1 / x$, where $x$ is the spiked concentration of DXT.

\subsubsection{Overall and Matrix Recovery}

The overall and matrix recoveries of DXT and IS from the samples containing brain microsomes $(0.2 \mathrm{mg} / \mathrm{mL}$ protein) were determined in five replicates of three concentrations from the calibration curve $(0.25,5$, and $50 \mathrm{nM})$. The overall recovery (recovery from protein precipitation plus matrix effect) was estimated by comparing samples and references prepared in the presence and absence of microsomes, respectively. The matrix recovery was estimated by preparing blank samples and references in the presence and absence of matrix, respectively, followed by protein precipitation and addition of DXT and IS directly to the resultant supernatants. In both cases, the absolute peak areas of DXT or IS in the samples were compared with those in their respective references, and recoveries were presented as percentages of the references. 


\subsection{DXT impurity in the DXM substrate from different sources}

The extent of DXT impurities in DXM stock solutions $(1000 \mu \mathrm{M})$, which were prepared from three different DXM-HBr powders and a DXM base reference standard (DXM-USP), were tested by quantitating DXT concentrations using the LC-MS/MS method. The extent of impurity was then calculated as the molar concentration of DXT impurity divided by the molar concentration of DXM, multiplied by 100 .

\subsection{Preparation of microsomes from whole rat brain}

Frozen whole brains from adult ( 8 to 12 -week old), male Sprague-Dawley rats were purchased from Innovative-Research (Novi, Michigan, USA). Whole brains were homogenized in ice-cold buffer (100 mM Tris, $0.2 \mathrm{mM}$ EDTA, and $1.15 \% \mathrm{KCl}$; $\mathrm{pH} 7.4)$ at a 1:10 ratio using an electric motor-driven Potter-Elvehjem Teflon homogenizer. Homogenate was spun at 1,300 $\mathrm{g}$ for 5 minutes at $4^{\circ} \mathrm{C}$. The supernatant was collected, and the pellet washed with the homogenizing buffer and centrifuged again at 1,300 g for 5 minutes. The supernatants were combined and spun at $21,000 \mathrm{~g}$ for 12 minutes at $4^{\circ} \mathrm{C}$ to pellet mitochondria. The supernatant was collected and spun at $110,000 \mathrm{~g}$ for 70 minutes to obtain microsomes. The supernatant was discarded, and the pellet was washed and centrifuged again using fresh homogenization buffer. The microsomal pellet was collected and re-suspended in a storage buffer (100 mM Tris, $0.2 \mathrm{mM}$ EDTA, $1.15 \% \mathrm{KCl}, 20 \%$ glycerol, $0.1 \mathrm{mM}$ dithiothreitol, $22 \mu \mathrm{M}$ butylated hydroxytoluene, and $0.1 \mathrm{mM}$ phenylmethylsulfonyl fluoride; $\mathrm{pH} 7.4$ ) and stored at $-80^{\circ} \mathrm{C}$ for later experiments. Total protein concentrations were estimated using the Bradford method.

\subsection{Determination of the CYP2D-mediated O-demethylase activity}

DXM stock solutions were prepared by dissolving the DXM-HBr and DXM-USP powders in water and $5 \mathrm{mM}$ excess $\mathrm{HCl}$ solutions, respectively. After an initial study to compare the DOD 
activities using DXM-HBr \#3 and DXM-USP stock solutions at a DXM concentration of 1000 $\mu \mathrm{M}$, all the MM experiments were conducted using DXM-USP at concentrations of 100, 200, 500, 1000, 1500, and $2000 \mu \mathrm{M}$. To determine the inter-animal variability, the MM curves were constructed using four different brain tissues . Microsomal protein $(5 \mu \mathrm{g})$ was preincubated at $37^{\circ} \mathrm{C}$ for 5 minutes in $100 \mathrm{mM}$ Tris- $\mathrm{HCl}$ buffer $\mathrm{pH} 7.4$ with DXM substrate in a final volume of $25 \mu \mathrm{L}$. The reaction was initiated by the addition of $1 \mathrm{mM}$ NADPH. After 20 minutes of incubation at $37^{\circ} \mathrm{C}$, reactions were terminated by the addition of ice-cold acetonitrile $(75 \mu \mathrm{L})$, containing $10 \mathrm{nM}$ IS $\left(\mathrm{d}_{3}\right.$-DXT). Each reaction mixture was paired with its own control sample, containing all the elements of the reaction mixture with the exception of NADPH. The reactions in the control samples were immediately (time zero) terminated by the addition of ice-cold acetonitrile containing internal standard. Samples were centrifuged, and the supernatants were loaded into HPLC vials for LC-MS/MS analysis. The nonlinear regression analysis of the metabolism rate-substrate concentration data was fitted to a one-enzyme MM model to estimate the maximum velocity $\left(\mathrm{V}_{\mathrm{max}}\right)$ and $\mathrm{MM}$ constant $\left(\mathrm{K}_{\mathrm{m}}\right)$ using GraphPad Prism software (La Jolla, CA, USA).

\subsection{Stability of DXT in brain microsomal incubations and during autosampler storage}

To confirm stability of the generated DXT in the brain microsomal incubations, DXT (5 nM) was added to the microsomal incubation samples, described above, in the presence of NADPH but without the addition of substrate. The concentration of DXT (5 nM) was selected to be close to the concentration generated near the $\mathrm{K}_{\mathrm{m}}$ of our reactions. The samples were incubated at $37^{\circ} \mathrm{C}$ and subjected to LC-MS/MS analysis at $0,5,10,15$, and 20 min after incubation $(n=3 /$ each time point). Additionally, the samples, after protein precipitation, were kept in the autosampler 
$\left(10^{\circ} \mathrm{C}\right)$ and re-injected 24 hours later to determine the autosampler stability of the processed samples.

\section{Results and discussion}

\subsection{UPLC-MS/MS assay characteristics}

Figure 2 depicts the chromatograms of brain microsomal matrix for a blank brain microsomal sample, the lowest concentration of DXT $(0.25 \mathrm{nM})$ in the calibration curve, and the IS $\left(\mathrm{d}_{3^{-}}\right.$ DXT). Under the chromatographic conditions described in the methods section, DXT and IS eluted at 2.75 min as sharp peaks with low baseline noises.

The overall and matrix recoveries of DXT from the brain microsomal samples at low, middle, and high concentrations in the calibration curve are presented in Table 1, along with their respective internal standard (single concentration of $10 \mathrm{nM}$ ). Whereas the matrix recovery is influenced by the matrix only, the overall recovery reflects both matrix recovery and recovery from the protein precipitation procedure. The recovery of DXT and IS from the matrix, based on the absolute peak areas, ranged from $91 \%-95 \%$ and $96 \%$ to $102 \%$, respectively, indicating a lack of matrix effect. Similarly, the overall recoveries of DXT ( $91 \%-106 \%)$ and IS (89\% $108 \%$ ) were relatively high, suggesting an almost complete recovery from the protein precipitation method and confirming the lack of matrix effect on the samples (Table 1). For both cases, the recoveries were independent of the concentration of DXT (one-way ANOVA). Most of the current LC-MS/MS assays that quantitate DXT have been developed for measurement of DXM and its metabolites in plasma [22] or blood [23] and require extraction procedures to remove substantial matrix effect of the plasma or blood. The lack of matrix effect in our studies, which uses protein precipitation, is most likely due to the fact that our micro-scale microsomal assay contains only $5 \mu \mathrm{g}$ of proteins, as opposed to substantial proteins in the plasma and blood. 
However, our protein precipitation method may not be suitable for plasma or blood samples because it may cause significant matrix effect.

Calibration curves constructed in the range of $0.25-100 \mathrm{nM}$ (prepared in brain microsomal matrix) were linear with $r^{2}$ values of $\geq 0.99$ for the inter- and intra-run experiments. The representative equation for the standard curves (calculated from the averages of the inter-day calibration curves) was $y=0.0337 x-0.00126$, where $y$ and $x$ refer to the DXT: IS peak ratio and the concentration of DXT, respectively. The results of intra- and inter-day accuracy and precision experiments are reported in Table 2. The values fell within the limits of the FDA guidelines; the accuracy was within $94.1-111 \%$, and the precision values (R.S.D.) were $\leq 14.9 \%$. Based on the accuracy and precision values (Table 2), the lower limit of quantitation (LLOQ) for DXT was $0.25 \mathrm{nM}$, which translates to an equivalent of $0.125 \mathrm{fmol}$ DXT on the column.

Previous studies of the CYP2D-mediated DOD activity in the brain have relied on GC-MS [7] or HPLC with UV [4], fluorescence [5, 6], electrochemical [10], or MS/MS [3] detectors for quantification of DXT. These assays reported LLOQs or detection limits between 2 fmol to 2 pmol, with the HPLC-MS/MS method [3] reporting the highest sensitivity. Others have also reported HPLC or LC methods coupled with tandem mass spectrometry for the DOD assay, mostly for microsomal samples from the liver $[2,24]$ or intestinal [20] tissues. However, these assays may not be directly transferrable to the brain microsomes because of low abundance of CYP450 in the brain tissue. The only reported LC-MS/MS assay for DOD activity in the brain [3] is based on an assay originally developed for the liver microsomes [24]. Although reporting a detection limit of $2 \mathrm{fmol}$, the assay [3] requires $50 \mu \mathrm{g}$ of microsomal protein and uses bucetin as an IS, which shows a different retention time than DXT [24]. The use of deuterated DXT as IS in our assay is more advantageous compared with an IS with a different structure, which may show 
a different response to matrix effect or inter- and intra-run changes to the sensitivity of the MS detector. Additionally, our LLOQ for DXT $(0.125 \mathrm{fmol})$ is a considerable improvement to the LLOQ reported in the literature for the DOD assay. The higher sensitivity of our assay, compared with the other MS/MS assays [2, 3, 20, 24] may be partly due to our use of UPLC instead of HPLC. Additionally, our method has a simpler sample preparation (protein precipitation with acetonitrile) compared to those methods that use a more complicated liquidliquid extraction method for determination of DOD activity in the brain [5-7, 10, 20].

\subsection{DXT impurity in the DXM substrates from different sources}

Almost all of the studies of DOD activity use DXM hydrobromide (DXM-HBr), which is significantly more water soluble than DXM base. However, when we tested three commercially available powders of DXM-HBr, we noticed measurable concentrations of DXT impurity in the substrate. When quantified, the concentrations of DXT in $1000 \mu \mathrm{M}$ stock solutions of the powders ranged from 4.17 to $9.72 \mathrm{nM}$, which translates to a very low impurity of $0.000417 \%$ to $0.000972 \%$, based on the molar concentrations of DXT and DXM (Table 3). We also purchased and tested an analytical reference standard of DXM base powder (DXM-USP). The DXM-USP was dissolved in dilute $\mathrm{HCl}$ solutions for solubility purposes. The concentration and extent of impurity of DXT in the DXM-USP were >10 fold lower than the corresponding values for the DXM-HBr powders (Table 3).

The relatively low level of impurity of DXT in the substrate powders (Table 3) may be insignificant for DOD activity assays in the liver microsomes, which have high DOD activity. However, the impurity could potentially lead to significant errors when the production rate of DXT is relatively low, as is the case with the brain microsomes. Therefore, we tested the effects of DXT impurities on the formation rate of DXT in brain microsomes using $1000 \mu \mathrm{M}$ 
concentrations of DXM-HBr \#3, which had the lowest degree of impurity among the three tested $\mathrm{HBr}$ powders (Table 3), and DXM-USP with a 10-fold lower impurity. Figures 3A and 3B demonstrate the chromatograms of DXT present in the DXM-HBr \#3 and DXM-USP powders, respectively, immediately (time zero) and 20 min after the incubation of the brain microsomal samples with $1000 \mu \mathrm{M}$ of the substrates. As expected from the data in Table 3 , the DXT impurity peak in the DXM-HBr \#3 sample $(4.36 \pm 0.22$ nM, Fig. 3A) was 10-fold larger $(\mathrm{p}<0.0001, n$ = 5) than that in the DXM-USP sample $(0.453 \pm 0.044$ nM, Fig. 3B $)$. Additionally, for the DXM$\mathrm{HBr} \# 3$ substrate, the DXT impurity peak appeared to substantially contribute to the DXT peak after 20 min of incubation with brain microsomes (Fig. 3A). However, the contribution of small impurity in the DXM-USP to the 20-min incubation sample seemed to be minimal (Fig. 3B).

The higher impurity in the DXM-HBr \#3 powder resulted in a significantly ( $\mathrm{p}<0.01$, twotailed unpaired t-test, $n=5$ ) higher (40\%) DOD activity with this substrate as compared with the activity after the incubation with DXM-USP (Fig. 3C). However, when the production of the metabolite by brain microsomes was normalized to the background peak at time zero, the DOD activities for the two substrates became similar (Fig. 3D). Therefore, for our incubation studies with brain microsomes, we used DXM-USP in addition to measurement of the DXT at both time zero and 20 min to account for the presence of any impurities.

\subsection{Optimization of DOD incubation conditions}

Figures 4A and 4B depict the brain microsomal activity of DOD as a function of time and microsomal protein concentrations, respectively. As demonstrated in Fig. 4A, the amount of metabolite formed was linear up to 40 min of incubation time in the presence of $0.2 \mathrm{mg} / \mathrm{mL}$ protein and $200 \mu \mathrm{M}$ DXM. Additionally, the formation rate was linear across the tested protein concentrations $(0.1,0.2,0.3$, and $0.4 \mathrm{mg} / \mathrm{mL})$ after $20 \mathrm{~min}$ incubation of the samples with 200 
$\mu \mathrm{M}$ DXM (Fig. 4B). From these experiments, we determined that the optimum incubation conditions for our kinetic experiments were $0.2 \mathrm{mg} / \mathrm{mL}$ brain microsomal protein $(5 \mu \mathrm{g}$ protein for an incubation volume of $25 \mu \mathrm{L}$ ) and $20 \mathrm{~min}$ of incubation time. Compared with our incubation method, which uses $5 \mu \mathrm{g}$ microsomal protein, previous studies estimating DOD activity in rat brain microsomes have used much higher brain microsomal proteins of $50 \mu \mathrm{g}$ [3], $250 \mu \mathrm{g}$ [4], or $1500 \mu \mathrm{g}$ [7]. This decrease in protein amount per reaction allows for the use of single rat brain microsomal preparation as opposed to the pooling of multiple brains to yield enough microsomal material for MM studies of multiple enzymes. Additionally, a reaction time of 20 minutes was sufficient to produce enough metabolite for the analysis, compared to the 1-2 hours' time typically needed $[3,4,7]$.

Figure $4 \mathrm{C}$ shows the stability of the metabolite under the optimized reaction conditions as a function of incubation time. As demonstrated (Fig. 4C), there were no significant changes in the DXT concentrations with time, which indicates that the metabolite is stable for up to 20 minutes of incubation with NADPH and $5 \mu \mathrm{g}$ of brain microsomal protein. Additionally, the re-injection of the same samples stored for 24 hours in the autosampler $\left(10^{\circ} \mathrm{C}\right)$ did not reveal any significant changes in the concentrations of DXT (Figure 4C) or the absolute peak values of the DXT and IS (data not shown) as a result of autosampler storage.

\subsection{Estimation of DOD kinetics in rat brain microsomes}

The kinetics of DOD activity in brain microsomes collected from four different animals are shown in Figure 4D. We observed an expected MM curve that plateaued between substrate concentrations of 1000 and $2000 \mu \mathrm{M}$. The estimated MM kinetic parameters (mean $\pm \mathrm{SD}, n=4$ animals) were a $\mathrm{V}_{\max }$ of $2.24 \pm 0.42 \mathrm{pmol} / \mathrm{min} / \mathrm{mg}$ and a $\mathrm{K}_{\mathrm{m}}$ of $282 \pm 62 \mu \mathrm{M}$. Only two other studies, Jolivalt et al. [4] and Voirol et al. [7], have reported DOD kinetics in rat brain 
microsomes. These studies used far higher protein amounts (250 and $1500 \mu \mathrm{g})$ and much longer incubation times (120 and 90 minutes), compared with our study (5 $\mu$ g protein and 20 min incubation time). Whereas Jolivalt et al. [4] reported $\mathrm{V}_{\max }$ and $\mathrm{K}_{\mathrm{m}}$ values of $1.40 \mathrm{pmol} / \mathrm{min} / \mathrm{mg}$ and $400 \mu \mathrm{M}$, respectively, a $\mathrm{V}_{\max }$ of $0.65 \mathrm{pmol} / \mathrm{min} / \mathrm{mg}$ and a $\mathrm{K}_{\mathrm{m}}$ of $120 \mu \mathrm{M}$ were reported by Voirol et al. [7]. Our estimated $\mathrm{K}_{\mathrm{m}}$ value $(282 \mu \mathrm{M})$ lies in between the values reported by these two studies $(120$ and $400 \mu \mathrm{M})$. However, the $\mathrm{V}_{\max }$ values reported in these studies are somewhat lower than our observations $(2.24 \mathrm{pmol} / \mathrm{min} / \mathrm{mg})$. In addition to these two studies, a study by Asai et al. [3] measured the DOD activity in the microsomes from the brain cerebellum, cortex, and hippocampus only at a single substrate concentration of $50 \mu \mathrm{M}$. In their study, the highest DOD activity was observed in the cerebellum microsomes, which was $0.03 \mathrm{pmol} / \mathrm{min} / \mathrm{mg}$. However, the DOD activity in the cortical and hippocampal microsomes was half of that in the cerebellum. This activity is far lower than what we would expect from our whole brain microsomal samples $(\sim 0.5 \mathrm{pmol} / \mathrm{min} / \mathrm{mg}$ at $100 \mu \mathrm{M}$ dextromethorphan, Fig. 4D). The lower DOD activities or $\mathrm{V}_{\max }$ reported in the literature for brain microsomes may be due to a variety of factors. First, all three studies [3, 4, 7] used an NADPH-regenerating system, which contained $\mathrm{MgCl}_{2}$ that can reportedly [7] inhibit CYP450 metabolism. In our preliminary studies, we also observed inhibition of DOD activity when using $\mathrm{MgCl}_{2}$ in our reaction buffer (data not shown). Additionally, these studies used longer incubation times of $60 \mathrm{~min}$ [3], $90 \mathrm{~min}$ [7], or $120 \mathrm{~min}$ [4]. Thus, the longer incubation times may be responsible for the lower metabolic capacity. This could be due to the inherent instability that has been reported for CYP450 in brain samples [10, $13]$.

In studies described here, we followed the rate of formation of DXT as opposed to the rate of decline in the concentrations of the substrate. This is because MM studies are normally carried 
out at substrate concentrations that are expected to remain almost constant during the incubation period. Indeed, the concentrations of DXT formed during our 20-min microsomal incubation time from substrate concentrations of $100-2000 \mu \mathrm{M}$ were on average equal to $2.32-8.39 \mathrm{nM}$, which are equal to $2.32 \%$ and $0.420 \%$ of the initial substrate concentrations, respectively. Therefore, the concentrations of the substrate remains virtually constant during the incubation period. 


\section{Conclusions}

In this communication, we have described a micro-scale incubation method and a sensitive and validated LC-MS/MS assay for the estimation of DEX demethylation activity in the rat brain microsomes. Collectively, these methods allowed us to substantially reduce the incubation volume, microsomal protein amount, and the length of incubation. The method was successfully applied to the estimation of CYP2D MM kinetics of the DOD activity in the brain microsomes. By requiring far less biological material and time, our method represents a significant improvement over the existing techniques for investigating CYP2D activity in rat brain microsomes.

\section{Acknowledgments}

This study was supported by funding from Chapman University School of Pharmacy, and by the American Liver Foundation's Postdoctoral Research Fellowship Award. 


\section{References}

[1] J.C. Stevens, S.A. Marsh, M.J. Zaya, K.J. Regina, K. Divakaran, M. Le, R.N. Hines, Developmental changes in human liver CYP2D6 expression, Drug Metab Dispos, 36 (2008) $1587-1593$.

[2] R.L. Walsky, R.S. Obach, Validated assays for human cytochrome P450 activities, Drug Metab Dispos, 32 (2004) 647-660.

[3] Y. Asai, H. Tanaka, M. Nadai, M. Katoh, Status epilepticus decreases brain cytochrome P450 2D4 expression in rats, J Pharm Sci, 107 (2018) 975-978.

[4] C. Jolivalt, A. Minn, M. Vincent-Viry, M.M. Galteau, G. Siest, Dextromethorphan Odemethylase activity in rat brain microsomes, Neurosci Lett, 187 (1995) 65-68.

[5] D.M. McMillan, R.F. Tyndale, Inducing rat brain CYP2D with nicotine increases the rate of codeine tolerance; predicting the rate of tolerance from acute analgesic response, Biochem Pharmacol, 145 (2017) 158-168.

[6] S. Miksys, F.B. Wadji, E.C. Tolledo, G. Remington, J.N. Nobrega, R.F. Tyndale, Rat brain CYP2D enzymatic metabolism alters acute and chronic haloperidol side-effects by different mechanisms, Prog Neuropsychopharmacol Biol Psychiatry, 78 (2017) 140-148.

[7] P. Voirol, M. Jonzier-Perey, F. Porchet, M.J. Reymond, R.C. Janzer, C. Bouras, H.W. Strobel, M. Kosel, C.B. Eap, P. Baumann, Cytochrome P-450 activities in human and rat brain microsomes, Brain Res, 855 (2000) 235-243.

[8] T. Hiroi, T. Chow, S. Imaoka, Y. Funae, Catalytic specificity of CYP2D isoforms in rat and human, Drug Metab Dispos, 30 (2002) 970-976.

[9] S. Miksys, Y. Rao, E.M. Sellers, M. Kwan, D. Mendis, R.F. Tyndale, Regional and cellular distribution of CYP2D subfamily members in rat brain, Xenobiotica, 30 (2000) 547-564. 
[10] R.F. Tyndale, Y. Li, N.Y. Li, E. Messina, S. Miksys, E.M. Sellers, Characterization of cytochrome P-450 2D1 activity in rat brain: high-affinity kinetics for dextromethorphan, Drug Metab Dispos, 27 (1999) 924-930.

[11] C. Ghosh, M. Hossain, J. Solanki, A. Dadas, N. Marchi, D. Janigro, Pathophysiological implications of neurovascular P450 in brain disorders, Drug Discov Today, 21 (2016) 16091619.

[12] D.M. McMillan, R.F. Tyndale, CYP-mediated drug metabolism in the brain impacts drug response, Pharmacol Ther, 184 (2018) 189-200.

[13] F. Toselli, P.R. Dodd, E.M. Gillam, Emerging roles for brain drug-metabolizing cytochrome P450 enzymes in neuropsychiatric conditions and responses to drugs, Drug Metab Rev, 48 (2016) 379-404.

[14] A. Mann, S. Miksys, A. Lee, D.C. Mash, R.F. Tyndale, Induction of the drug metabolizing enzyme CYP2D in monkey brain by chronic nicotine treatment, Neuropharmacology, 55 (2008) 1147-1155.

[15] D.M. McMillan, R.F. Tyndale, Nicotine increases codeine analgesia through the induction of brain CYP2D and central activation of codeine to morphine, Neuropsychopharmacology, 40 (2015) 1804-1812.

[16] J. Yue, S. Miksys, E. Hoffmann, R.F. Tyndale, Chronic nicotine treatment induces rat CYP2D in the brain but not in the liver: an investigation of induction and time course, $\mathrm{J}$ Psychiatry Neurosci, 33 (2008) 54-63.

[17] K. Zhou, J.Y. Khokhar, B. Zhao, R.F. Tyndale, First demonstration that brain CYP2Dmediated opiate metabolic activation alters analgesia in vivo, Biochem Pharmacol, 85 (2013) 1848-1855. 
[18] S.L. Miksys, R.F. Tyndale, Drug-metabolizing cytochrome P450s in the brain, J Psychiatry Neurosci, 27 (2002) 406-415.

[19] V. Ravindranath, H.K. Anandatheerthavarada, Preparation of brain microsomes with cytochrome P450 activity using calcium aggregation method, Anal Biochem, 187 (1990) 310-313.

[20] D. Busch, A. Fritz, L.I. Partecke, C.D. Heidecke, S. Oswald, LC-MS/MS method for the simultaneous quantification of intestinal CYP and UGT activity, J Pharm Biomed Anal, 155 (2018) 194-201.

[21] D. Zimmer, New US FDA draft guidance on bioanalytical method validation versus current FDA and EMA guidelines: chromatographic methods and ISR, Bioanalysis, 6 (2014) 13-19.

[22] J.L. Donato, F. Koizumi, A.S. Pereira, G.D. Mendes, G. De Nucci, Simultaneous determination of dextromethorphan, dextrorphan and doxylamine in human plasma by HPLC coupled to electrospray ionization tandem mass spectrometry: application to a pharmacokinetic study, J. Chromatogr. B, 899 (2012) 46-56.

[23] X. Liang, Y. Li, M. Barfield, Q.C. Ji, Study of dried blood spots technique for the determination of dextromethorphan and its metabolite dextrorphan in human whole blood by LC-MS/MS, J. Chromatogr. B, 877 (2009) 799-806.

[24] T. Zhang, Y. Zhu, C. Gunaratna, Rapid and quantitative determination of metabolites from multiple cytochrome P450 probe substrates by gradient liquid chromatography-electrospray ionization-ion trap mass spectrometry, J Chromatogr B Analyt Technol Biomed Life Sci, 780 (2002) 371-379. 


\section{Table 1}

Overall and matrix recoveries (mean \pm SD) of dextrorphan and internal standard (IS) from the brain microsomal samples at low $(0.25 \mathrm{nM})$, medium $(5 \mathrm{nM})$, and high $(50 \mathrm{nM})$ concentrations of DXT in the calibration curves $(n=5)$. The IS concentration was the same $(10 \mathrm{nM})$ in all the samples.

\begin{tabular}{|c|c|c|c|c|}
\hline \multirow{2}{*}{$\begin{array}{l}\text { Concentration } \\
(\mathrm{nM})\end{array}$} & \multicolumn{2}{|c|}{ Overall Recovery (\%) } & \multicolumn{2}{|c|}{ Matrix Recovery (\%) } \\
\hline & Dextrorphan & IS & Dextrorphan & IS \\
\hline 0.25 & $106 \pm 18$ & $108 \pm 8$ & 25.5 & $95.9 \pm 3.76$ \\
\hline 5 & $94.1 \pm 11.5$ & $96.2 \pm 11.5$ & $94.6 \pm 8.24$ & $96.2 \pm 5.94$ \\
\hline 50 & $91.0 \pm 16.1$ & $89.4 \pm 15.3$ & $95.3 \pm 4.83$ & $102 \pm 4.64$ \\
\hline
\end{tabular}




\section{Table 2}

Intra- and inter-run accuracy and precision values of the lowest $(0.25 \mathrm{nM})$, middle $(5 \mathrm{nM})$, and highest $(100 \mathrm{nM})$ concentrations of dextrorphan in calibration curves for brain microsomes $(n=5)$.

\begin{tabular}{llllll}
\hline & Intra-run & & & Inter-run & \\
\cline { 2 - 3 } \cline { 5 - 6 } Concentration $(\mathrm{nM})$ & Accuracy & $\begin{array}{l}\text { R.S.D. } \\
(\%)\end{array}$ & & Accuracy & $\begin{array}{l}\text { R.S.D. } \\
(\%)\end{array}$ \\
\hline 0.25 & 102 & 14.9 & 111 & 14.5 \\
5 & 98.2 & 6.5 & & 94.1 & 7.8 \\
100 & 100 & 9.4 & 101 & 1.6 \\
\hline
\end{tabular}




\section{Table 3}

Extent of dextrorphan (DXT) impurity (mean \pm SD) in 4 different commercially-available powders of dextromethorphan $(n=5)$.

\begin{tabular}{lll}
\hline \multirow{3}{*}{$\begin{array}{l}\text { DXM Stock } \\
(1000 \mu \mathrm{M})\end{array}$} & \multicolumn{2}{c}{ DXT impurity } \\
\cline { 2 - 3 } & Conc. $(\mathrm{nM})$ & $\%$ \\
\hline DXM-HBr \#1 & $9.72 \pm 0.68$ & $0.000972 \pm 0.000068$ \\
DXM-HBr \#2 & $9.42 \pm 0.23$ & $0.000942 \pm 0.000023$ \\
DXM-HBr \#3 & $4.17 \pm 0.11$ & $0.000417 \pm 0.000011$ \\
DXM-USP & $0.401 \pm 0.044$ & $0.0000401 \pm 0.0000044$ \\
\hline
\end{tabular}




\section{Figure legends}

Figure 1. Schematic of the dextromethorphan-O-demethylase (DOD) reaction by CYP2D enzyme,

where dextromethorphan (DXM) is converted to dextrorphan (DXT).

Figure 2. Representative chromatograms of a blank brain microsomal sample (A), the lowest dextrorphan concentration $(0.25 \mathrm{nM})$ in the calibration curve $(\mathrm{B})$, and the internal standard $(\mathrm{C})$.

Figure 3. Effects of DXT impurity in the substrate on the DOD assay. (A) and (B): Representative chromatograms of dextrorphan in the brain microsomes immediately and $20 \mathrm{~min}$ following microsomal incubation with $100 \mu \mathrm{M}$ DXM-HBr \#3 (A) or DXM-USP (B); (C) and (D): The estimated rates of metabolite (DXT) formation after $20 \mathrm{~min}$ of brain microsomal incubation at $37^{\circ} \mathrm{C}$ without (C) or with (D) correction for the impurity. ** denotes $\mathrm{p}<0.01$, based on unpaired, two-tailed t test.

Figure 4. DOD assay characteristics (A-C) and Michaelis-Menten (MM) kinetics (D) in rat brain microsomal incubations. For time linearity $(\mathrm{A})$, rat brain microsomes $(n=4)$ were incubated at $0.2 \mathrm{mg} / \mathrm{mL}$ protein with $200 \mu \mathrm{M}$ DXM. For protein linearity $(\mathrm{B})$, rat brain microsomes $(n=4)$ were incubated at varying protein concentrations with $200 \mu \mathrm{M}$ DXM for 20 minutes. For metabolite stability $(\mathrm{C})$, dextrorphan $(5 \mathrm{nM})$ was incubated $\left(37^{\circ} \mathrm{C}\right)$ in brain microsomes $(0.2$ $\mathrm{mg} / \mathrm{mL})$ in the presence of NADPH $(1 \mathrm{mM})$, and samples $(n=3)$ were analyzed immediately (First Injection) and after 24 hours of storage $\left(10^{\circ} \mathrm{C}\right)$ in the autosampler (Second Injection). For MM kinetics (D), incubations were carried out at $37^{\circ} \mathrm{C}$ at $0.2 \mathrm{mg} / \mathrm{mL}$ protein in a final volume of $25 \mu \mathrm{L}$ with $1 \mathrm{mM}$ NADPH for 20 minutes ( $n=4$ different brains). Symbols and bars represent mean and SD of experimental data, respectively, and the lines are based on linear regression 
analysis (A, B, and C) or a one-enzyme, Michaelis-Menten fit to the data (D). The slopes of the linear regression lines in $\mathrm{C}$ were not significantly different from zero. 

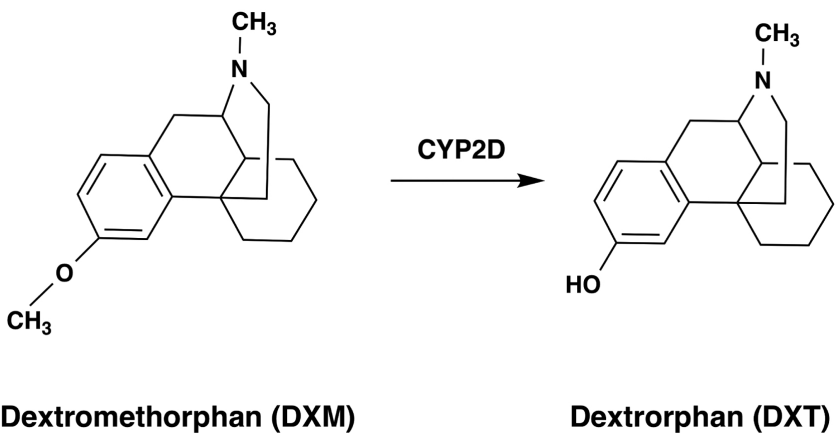

Dextromethorphan (DXM)

Dextrorphan (DXT)

Figure 1 
A

B

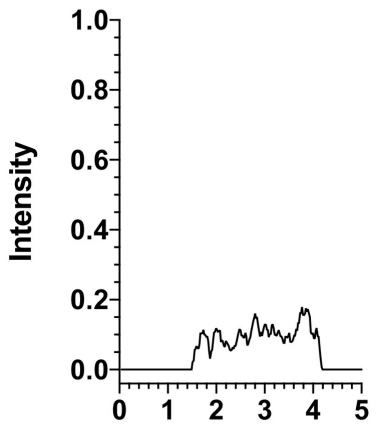

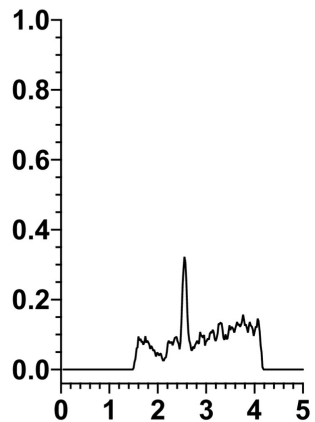

Time (Minutes)
C

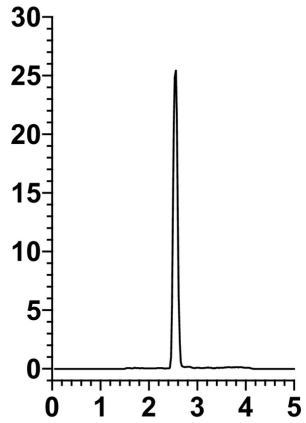

Figure 2 
A (DXM-HBr)

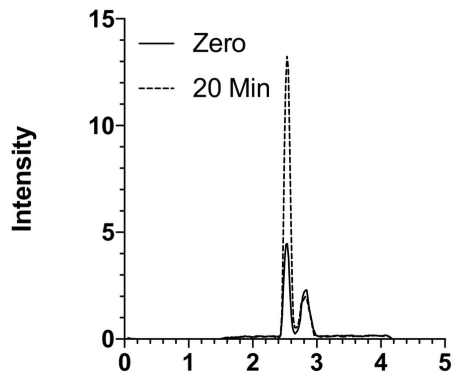

C (Uncorrected Rate)

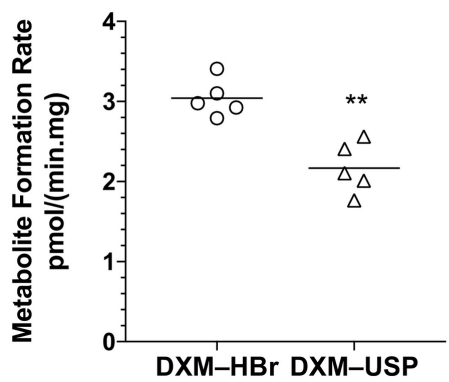

\section{B (DXM-USP)}

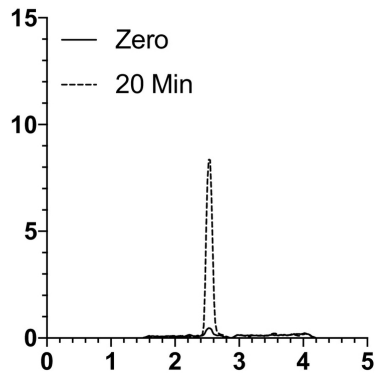

D (Corrected Rate)

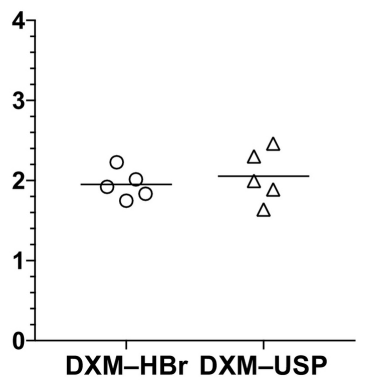

Figure 3 


\section{A (Time Linearity)}

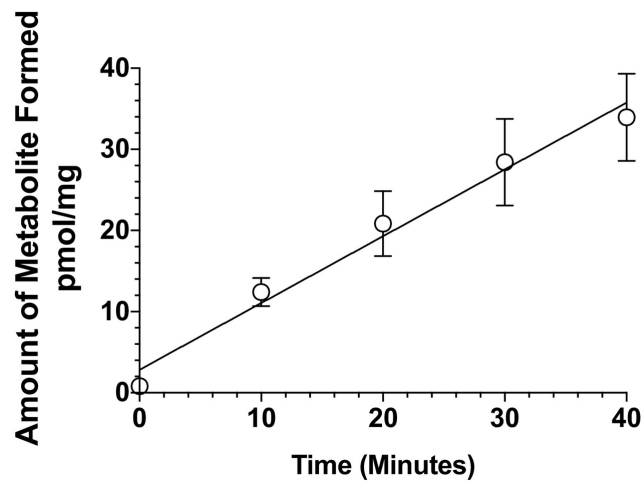

C (Metabolite Stability)

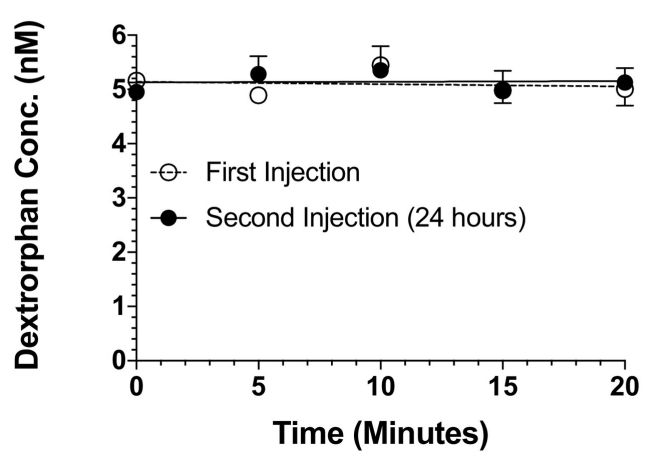

A (Protein Linearity)

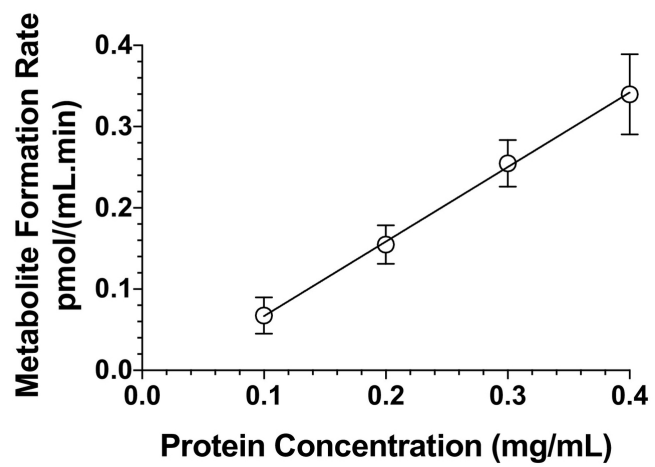

D (MM Kinetics)

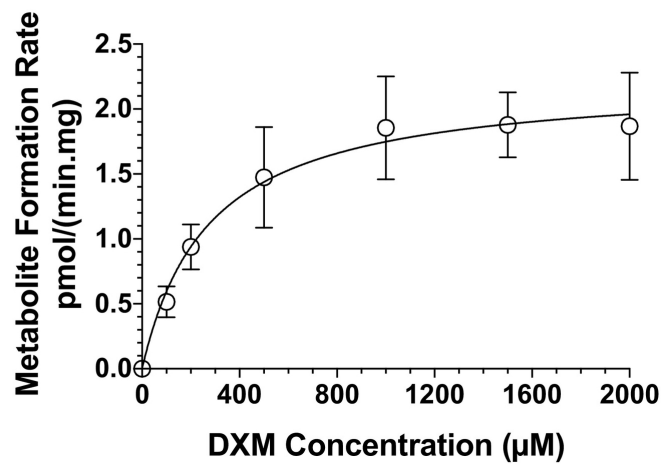

